\title{
SP-D polymorphisms and the risk of COPD
}

\author{
Tania A. Shakoori ${ }^{\mathrm{a}, *}$, Don D. Sin ${ }^{\mathrm{b}}$, S. Nazim Hussain Bokhari ${ }^{\mathrm{a}}$, Farkhanda Ghafoor ${ }^{\mathrm{c}}$ and \\ A.R. Shakoori ${ }^{\mathrm{d}}$ \\ ${ }^{a}$ University of Health Science, Lahore, Pakistan \\ ${ }^{\mathrm{b}}$ Faculty of Medicine, University of British Columbia, Vancouver, BC, Canada \\ ${ }^{\mathrm{c}}$ National Health Research Complex, SZMC, Lahore, Pakistan \\ ${ }^{\mathrm{d}}$ School of Biological Sciences, University of the Punjab, Lahore, Pakistan
}

\begin{abstract}
Introduction: There are limited data linking serum levels of surfactant protein D, its genetic polymorphisms to the risk of Chronic Obstructive Pulmonary Disease (COPD).

Objectives: We sought to investigate these relationships using a case control study design.

Methods: Post bronchodilator values of FEV1/FVC $<0.7$ were used to diagnose COPD patients $(n=115)$. Controls were healthy subjects with normal spirometry $(n=106)$ Single nucleotide polymorphisms (rs721917, rs2243639, rs3088308) were genotyped using polymerase chain reaction (PCR) and restriction analysis. Serum SP-D levels were measured using a specific immunoassay.

Results: Allele 'A' at rs3088308 ( $p<0.00, B=-0.41)$ and 'C' allele at rs721917 $(p=0.03 ; B=-0.30)$ were associated with reduced serum SP-D levels. Genotype 'T/T' at rs721917 was significantly associated with risk of COPD $(p=0.01)$. Patients with repeat exacerbations had significantly higher serum SP-D even after adjusting for genetic factors.

Conclusions: We report for the first time that rs 3088308 is an important factor influencing systemic SP-D levels and confirm the previous association of rs721917 to the risk of COPD and serum SP-D levels.
\end{abstract}

Keywords: Surfactant protein D, SP-D SNPs, serum SP-D levels, COPD risk, SP-D haplotypes

\section{Introduction}

Chronic Obstructive Pulmonary Disease (COPD) is a preventable and treatable disease with significant extrapulmonary effects associated with progressive airflow limitation and abnormal inflammatory response [1]. The incomplete understanding of its pathophysiology is a major hurdle in the development of effective therapy. Many mechanisms have been proposed to explain the pathophysiology of COPD. These include protease/antiprotease imbalance [2], oxidant/antioxidant disturbances [3], persistent abnormal inflammatory response [4], accelerated unopposed apoptosis [5], autoimmunity [6,7], histone deacetylation leading to transcription of proinflammatory factors [8] and prema-

* Corresponding author: Dr. Tania Ahmed Shakoori, Ph.D., University of Health Science, Lahore, Pakistan. E-mail: drtaniashakoori @ yahoo.com. ture aging of the lung [9]. Surfactant protein D (SP-D) has immunomodulatory functions $[10,11]$. By keeping a potentially aggressive inflammatory reaction in check, SP-D diminishes production of proteases and oxidants [12]. In addition it causes effective efferocytosis and prevents autoantibody formation [13-15]. SP-D may be an important effector molecule in the pathogenesis of COPD. SNPs rs721917 rs2243639 and rs3088308 [16,17] were chosen to be genotyped in COPD patients and controls in order to determine their association with risk of COPD and serum SP-D levels. Each of these SNPs is from one of the three main functional domains of the protein and together they regulate the various components of SP-D.

Rs721917 is associated with increased susceptibility to tuberculosis [18] Influenza A virus [19] infection, allergic rhinitis [20], COPD [21], respiratory syncitial virus (RSV) infection in infants [17], atopy [22] and blood levels of SP-D [23]. Rs2243639, on the other hand, has been associated with ulcerative colitis [24] 
Table 1

Primer sequences, restriction enzymes and restriction products for the three SNPs

\begin{tabular}{|c|c|c|c|c|c|c|}
\hline SNP ID & Primer pairs & Annealing temperatures & PCR product & Enzyme & For major allele & For minor allele \\
\hline rs3088308 & $\begin{array}{l}\text { 5'ACGGAGGCACAGCTGCTG-3' } \\
\text { 5'-GGAAAGCAGCCTCGTTCT-3' }\end{array}$ & $54^{\circ} \mathrm{C}$ & $115 \mathrm{bp}$ & MnlI & 54,42 and $19 \mathrm{bp}$ & 96 and $19 \mathrm{bp}$ \\
\hline rs721917 & $\begin{array}{l}\text { 5'CCCCATAGCAGAGGACAGAA3', } \\
\text { 5'CCAGGGTGCAAGCACTGGAC3' }\end{array}$ & $61^{\circ} \mathrm{C}$ & $238 \mathrm{bp}$ & HруCH4 IV & Uncut (238 bp) & 217 and $21 \mathrm{bp}$ \\
\hline rs2243639 & $\begin{array}{l}\text { 5'-CCСCАCTTCTCTCTCTGACC-3' } \\
\text { 5'-СТGCTCACCTGCTGCCCCCG3' }\end{array}$ & $56^{\circ} \mathrm{C}$ & $238 \mathrm{bp}$ & BstU1 & 165 and 73 bp & 145,73 and $20 \mathrm{bp}$ \\
\hline
\end{tabular}

and risk of respiratory syncytial virus infection (RSV) in neonates [25]. No clinical associations have yet been reported for rs3088308.

\section{Methods}

\subsection{Subjects}

We collected 106 controls from the general population of Lahore through advertising via posters at various public places in the city. One hundred and fifteen (115) cases were chosen from the inpatient wards and outpatient departments of Shaikh Zayed Medical Complex (SZMC) and Gulab Devi Chest Hospital, Lahore. The research project was approved by the ethical and scientific committees of both these hospitals prior to start of sampling. The inclusion criteria for cases were a clinical history suggestive of COPD (including breathlessness, chronic cough and sputum) along with airflow limitation as demonstrated by electronic spirometry (Spirolab 2, SDI Diagnostics, 10 Hampden Drive, Easton, MA 02375). Airflow limitation was diagnosed if FEV1/FVC ('Forced Expiratory Volume in 1 second' to 'Forced Vital Capacity ratio') was less than 0.7 after administration of salbutamol inhaler (200 $\mu \mathrm{g}$, Salbo, Getz Pharma, KIA, Karachi, Pakistan). The disease was staged according to FEV1\%predicted (Forced Expiratory Volume in 1 second percentage of predicted) as recommended by the GOLD committee [1]. The inclusion criteria for controls were the absence of respiratory symptoms and no airflow obstruction on spirometry. Exacerbations were diagnosed by a history of increase in dyspnoea, sputum volume or change of sputum colour as compared to the patients' routine [26]. All subjects (cases and controls) were Pakistani Punjabi men, 26 to 74 years old. Informed consent was obtained from each subject.

\subsection{Sampling}

Ten millilitres of venous blood was drawn from each subject. Five millilitre was allowed to clot and serum extracted, while the remaining $5 \mathrm{ml}$ was collected in EDTA (Ethylene Diamine Tetraacetic Acid) vacutainer tubes and used to isolate DNA.

\subsection{Genotyping}

DNA was extracted from whole blood manually using a 'salting out' procedure [27]. Relevant fragments of DNA were amplified by polymerase chain reaction using sets of primers as shown in Table 1 [28]. PCR was performed in a thermocycler (Eppendorf Mastercycler ${ }^{\circledR}$ Personal, USA). The reaction mixtures for the three sets of primers are shown in Table 1. PCR cycle was optimized so that the three primer pairs amplified their respective PCR products at the same set of temperatures. Briefly, initial denaturation took place at $95^{\circ} \mathrm{C}$ for 3 minutes, followed by subsequent denaturation at $94^{\circ} \mathrm{C}$ for 45 seconds and annealing at $61^{\circ} \mathrm{C}$ for another 45 seconds. Finally renaturation occurred at $72^{\circ} \mathrm{C}$ for 45 seconds and the cycle repeated itself 35 times until final extension step at $74^{\circ} \mathrm{C}$ ( 5 minutes). Each fragment was restricted by a specific restriction enzyme as described previously by Kreuger et al. [28] (Table 1). Briefly, the 115 base pair PCR product for rs3088308 was cleaved by MnI1 into 3 fragments (54, 42 and 19 base pairs) for the major allele and 2 fragments (96 and 19 base pairs) for the minor allele (Fig. 1). The 238 base pair PCR product for rs721917 was cleaved by HpyCH4IV into 2 fragments in case of the minor allele and remained intact in the case of major allele (Fig. 2). Finally the 238 base pair PCR product for rs2243639 was restricted by BstU1 into 165 and 73 base pairs fragments for the major allele and 3 fragments (145, 73 and 20 base pairs) in case of minor allele (Fig. 3). Restriction samples were incubated for 6-12 hours as required to ensure proper digestion. Restriction fragments were visualized in $12 \%$ polyacrylamide gel in TBE buffer and stained with ethidium bromide or silver nitrate.

Random samples were genotyped twice for quality assurance. For rs721917 the major allele remains undigested. Comparison with restriction samples pos- 


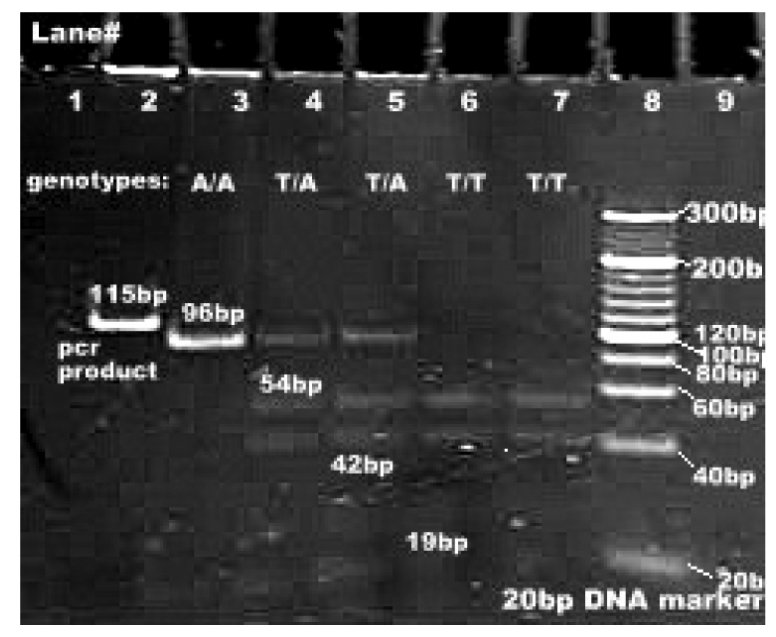

Fig. 1. $12 \%$ polyacrylamide gel (ethidium bromide stained) showing restriction analysis of PCR product for SNP, rs3088308 (115bp) by the enzyme MnlI. A/A genotype shows two bands of 96bp and 19bp in lane 3, T/T genotype shows three bands of 54, 42 and 19 base pairs (lanes 6 and 7), whereas all 4 bands (96, 54, 42 and 19 base pairs) are visible in case of T/A (lanes 4 and 5). Lane 2 shows the unrestricted PCR product and lane 1 is empty. Lane 8 shows $20 \mathrm{bp}$ DNA ladder. Due to prolonged running of the gels the 19 base pair restriction bands and the 20 base pair band of the DNA ladder are only faintly visible.

sessing the minor allele which were digested using the same mastermix of the enzyme and buffer as the samples with major allele, was used to ensure that lack of digestion was indeed due to the presence of major allele and not because of failure of the enzyme.

\subsection{Elisa}

The SP-D assay was performed in Immunoassay Lab. of National Health Research Complex, SZMC, Lahore. Commercial enzyme linked immunosorbent assay kits (BioVendor - Laboratorní medicína a.s. CT Park Modrice, Evropska 87366442 Modrice, Czech Republic) were used. Standards, quality controls and patient samples were run in duplicates. All procedures were carried out observing temperature conditions detailed in assay procedure. In brief, diluted samples were incubated in microplate wells pre-coated with monoclonal antihuman surfactant protein D antibody. After overnight incubation and washing, HRP conjugate was applied and another two hour incubation with adhered surfactant protein D was carried out. After washing the wells, the remaining HRP conjugate was allowed to react with the substrate solution (TMB). An acidic 'stop solution' was added to thwart the reaction and absorbance of the yellow product was recorded. The absorbance rep-

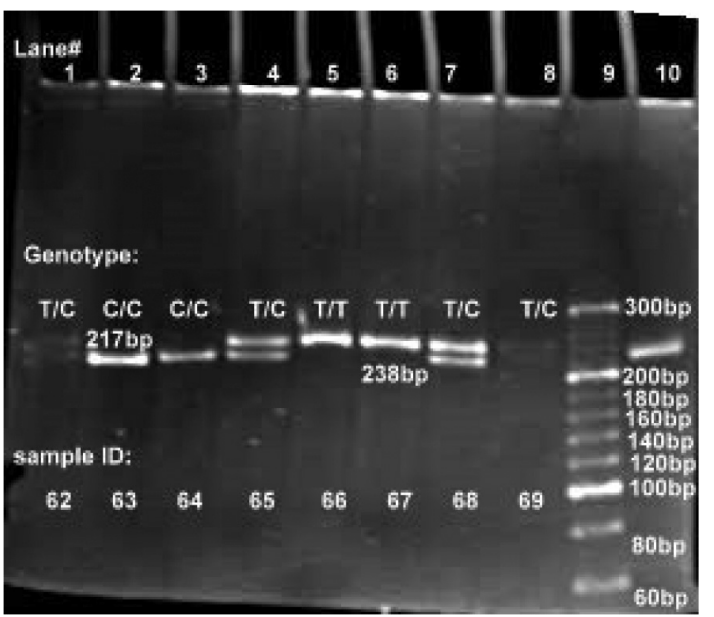

Fig. 2. $12 \%$ polyacrylamide gel (stained with ethidium bromide) showing restriction analysis of PCR product for rs721917 (238bp) by the enzyme HpyCH4IV. T/T genotype shows the uncut PCR product of 238 base pairs (lanes 5 and 6), $\mathrm{C} / \mathrm{C}$ genotype shows two restriction bands of 217 and 21 base pairs (lanes 2 and 3), whereas all 3 bands (238,217 and 21 base pairs) are visible in case of heterozygous genotype T/C (lanes 1,4,7 and 8). Lane 10 shows the unrestricted PCR product of 238 base pairs. Lane 9 shows the 20bp DNA ladder. The 21 base pair restriction bands and the 20 and 40 base pair bands of the DNA ladder have run out of the gel due to protracted electrophoresis.

resented the concentration of SP-D. The OD (optical density) values were plotted against concentrations of standards to generate a standard curve. Concentrations of unknown samples were determined by means of this standard curve. Throughout the assay procedure, assay precision was maintained by using calibrated micro pipettes and multi channel pipettes from Gilson and washing was done with automatic plate washer.

\subsection{Statistical analysis}

Hardy Weinberg equilibrium, genotype, allele and haplotype frequencies were calculated using SHesis software [30]. Chi square fisher exact test and odds ratio were calculated to test association of the genotypes alleles with COPD and to check for deviations from HWE. SPSS 17 was used for the rest of the analysis. Continuous variables were expressed as mean \pm SD. Binary logistic regression was applied to explore the relationship of age, smoking history and the genotypes of SNP rs721917 with risk of COPD. Serum levels of SP-D across different genotypes were compared using ANOVA. Multiple linear regression analysis was performed to analyse the effect of exacerbation status, steroid intake, smoking status, 'A' allele at rs3088308, $\mathrm{C}$ allele at rs721917, BMI, age, and FEV1\% of predicted on serum SP-D levels. For the purposes of re- 
Table 2

Characteristics of study subjects

\begin{tabular}{lll}
\hline Characteristic & Controls & COPD \\
\hline Subjects (n) & 115 & 106 \\
Age-yrs (mean \pm SD) & $37 \pm 11$ & $61 \pm 13$ \\
Smoking status & 15 never-smokers, 8 ex-smokers, 92 current smokers & 4 never smokers, 58 ex-smokers, 44 current smokers \\
Mean pack-years* & $18 \pm 17$ & $48 \pm 31$ \\
BMI kg/m 2 & $25 \pm 5$ & $21 \pm 4$ \\
FEV $1 /$ FVC \% & $84 \pm 5$ & $53 \pm 14$ \\
FEV $\%$ predicted & $97 \pm 15$ & $44 \pm 19$ \\
SP-D levels (ng/mL) & $121.5 \pm 61$ & $150.4 \pm 97$ \\
\hline
\end{tabular}

* Mean pack years include never smokers.

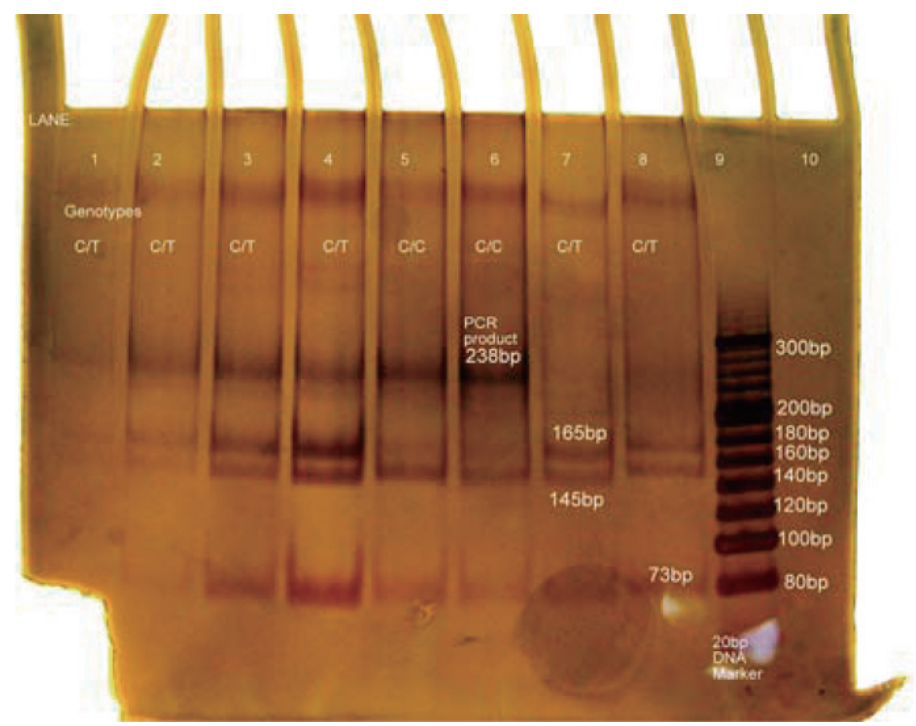

Fig. 3. 12\% polyacrylamide gel (after silver staining) showing restriction of PCR product for SNP rs 2243639 by the enzyme BstU1. 145 and 73 bp bands are visible in lanes 5 and 6 showing the C/C genotype. T/T genotype is not seen in this gel. Heterozygous genotype is seen in lanes 1 , $2,3,4,7$ and 8 as is indicated by bands of 165 and 145 base pairs. (20 bp bands and DNA ladder bands less than $80 \mathrm{bp}$ have 'run out' of the gel during the course of the electrophoresis).

gression, SP-D levels, age and BMI were transformed to their natural $\log$ to mitigate the effect of outliers. A 'p' value of less than 0.05 was considered statistically significant.

\section{Results}

\subsection{Subjects}

All subjects were Pakistani Punjabi men. Their characteristics are shown in Table 2.

\subsubsection{Genotypes and allele frequencies}

Results of PCR and restriction analysis revealed genotypes and allele frequencies (Table 3, Fig. 4). For the SNP rs721917, allele T was more frequent amongst cases (57.41 versus $48.8 \%)$ whereas allele C $(51.19 \%$ versus $42.59 \%)$ and genotype $\mathrm{C} / \mathrm{C}(21.4 \%$ versus $7.4 \%)$ was more common in the controls group. The genotype distribution in controls conformed to HWE $(p=0.08)$ but deviated significantly from it in cases $(p<0.001)$. Chi square test showed the difference in allele frequencies to be significant at $p=0.038$. There was no significant difference in the case of rs2243639 and rs3088308 the genotype or allele distribution between cases and controls did not differ significantly when tested with Chi square.

\subsubsection{Haplotypes}

Haplotype T T A (alleles in rs3088308, rs721917 and rs2243639 respectively) was significantly less frequent in COPD cases $(8.8 \%)$ as compared to controls (29\%) at $p=0.03$ with an odds ratio of 0.236 (95\% CI 0.057 to 0.975$)$. 
Table 3

Genotypes and allele frequencies in cases and control

\begin{tabular}{|c|c|c|c|c|c|}
\hline & & $\begin{array}{c}\text { Controls } \\
(n=106) \\
\end{array}$ & $\begin{array}{c}\text { COPD } \\
(n=115) \\
\end{array}$ & $\begin{array}{c}\text { 'p' for difference in } \\
\text { allele/genotype frequencies }\end{array}$ & $\begin{array}{l}\text { 'p' for HWE test } \\
\text { (controls/cases) }\end{array}$ \\
\hline \multicolumn{6}{|l|}{$r s 3088308$} \\
\hline \multirow[t]{3}{*}{ Genotypes (\%): } & $\mathrm{T} / \mathrm{T}$ & 58.4 & 65.1 & 0.31 & $0.04 / 0.35$ \\
\hline & $\mathrm{A} / \mathrm{T}$ & 29.4 & 30.3 & & \\
\hline & $\mathrm{A} / \mathrm{A}$ & 11.2 & 5.5 & & \\
\hline \multirow[t]{2}{*}{ Allele frequencies $(\%)$} & $\mathrm{T}$ & 73.6 & 79.6 & 0.14 & \\
\hline & A & 26.4 & 20.2 & & \\
\hline \multicolumn{6}{|l|}{$r s 721917^{*}$} \\
\hline \multirow[t]{3}{*}{ Genotypes (\%): } & $\mathrm{T} / \mathrm{T}$ & 19.0 & 22.2 & 0.038 & $0.08 /<0.001$ \\
\hline & $\mathrm{T} / \mathrm{C}$ & 59.5 & 70.4 & & \\
\hline & $\mathrm{C} / \mathrm{C}$ & 21.4 & 7.4 & & \\
\hline \multirow[t]{2}{*}{ Alelle frequencies (\%) } & $\mathrm{T}$ & 48.8 & 57.4 & 0.12 & \\
\hline & $\mathrm{C}$ & 51.2 & 42.6 & & \\
\hline \multicolumn{6}{|l|}{$r s 2243639$} \\
\hline \multirow[t]{3}{*}{ Genotypes (\%): } & $\mathrm{C} / \mathrm{C}$ & 14.3 & 14.3 & 0.50 & $0.66 / 0.50$ \\
\hline & $\mathrm{C} / \mathrm{T}$ & 57.1 & 50.8 & & \\
\hline & $\mathrm{T} / \mathrm{T}$ & 11.9 & 11.9 & & \\
\hline \multirow[t]{2}{*}{ Allele frequencies $(\%)$} & $\mathrm{C}$ & 42.9 & 52.7 & 0.15 & \\
\hline & $\mathrm{T}$ & 57.1 & 37.3 & & \\
\hline
\end{tabular}

* Genotyping results were available for 80 cases and 85 controls for rs721917.

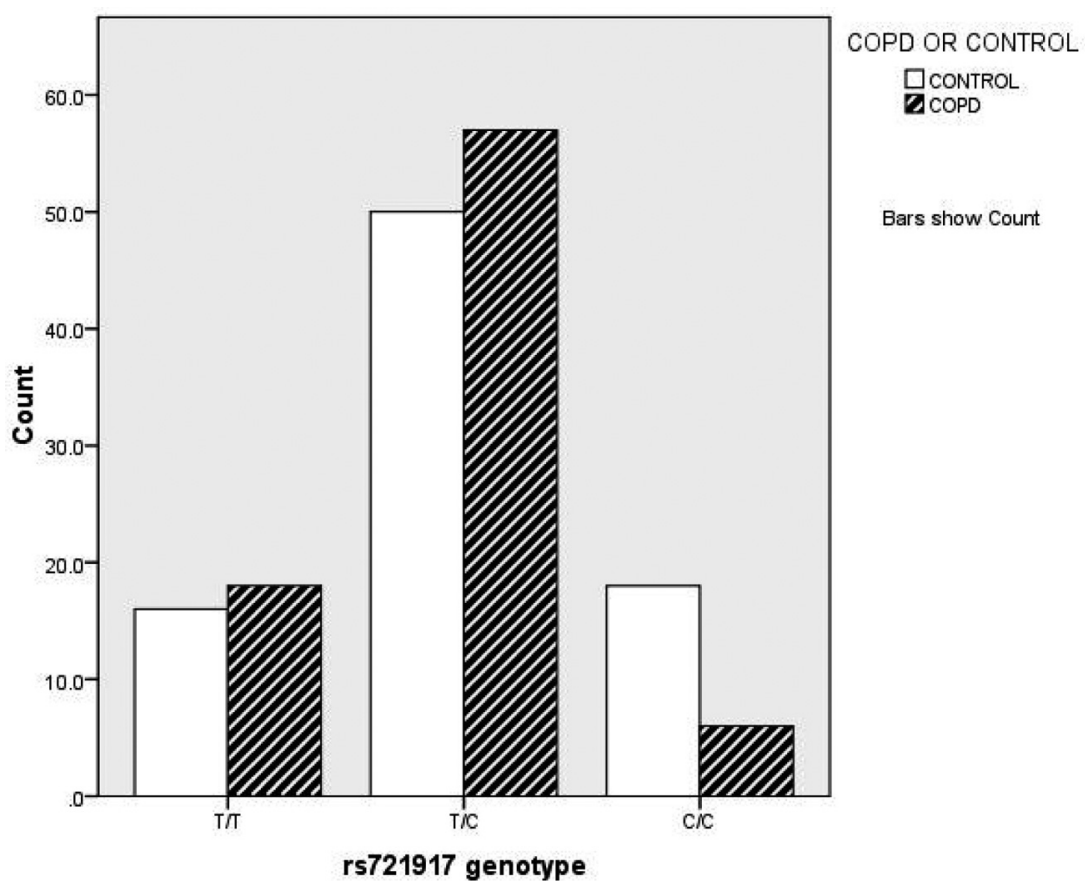

Fig. 4. Distribution of genotypes of SNP rs721917 ( $p=0.038)$. The dots represent outliers.

\subsubsection{Logistic regression for SNP alleles as risk factors for $C O P D$}

Binary logistic regression verified genotype $\mathrm{T} / \mathrm{T}$ of rs721917 as a significant risk factor for COPD $(B=$ $+2.4, p=0.01$, odds ratio $=11.17)$ along with advanced age $(B=+0.15, p=0.00$, odds ratio $=1.16)$ as shown in Table 4. The logistic regression model fitted the data adequately as is mirrored by the Hosmer and Lemeshow Test.

\subsubsection{Serum $S P-D$ levels and $S N P s$}

Mean SP-D serum levels differed significantly between the different genotypes of rs3088308 and rs721917 (Table 5, Fig. 5). For rs3088308 the serum 
Table 4

Genetic and environmental risk factors for development of COPD

\begin{tabular}{lccccc}
\hline Risk factors for COPD & B & S.E. & 'P' & Odds ratio & $95 \%$ CI \\
\hline Age (years) & 0.15 & 0.03 & $<0.001$ & 1.16 & $1.10-1.23$ \\
Smoking (Pack years) & 0.02 & 0.01 & 0.11 & 1.02 & $0.99-1.05$ \\
rs721917 (C/C) & - & - & 0.04 & - & - \\
rs721917 (T/T) & 2.41 & 0.95 & $0.01^{*}$ & 11.17 & $1.75-71.18$ \\
rs721917 (C/T) & 1.34 & 0.80 & 0.10 & 3.80 & $0.79-18.39$ \\
\hline
\end{tabular}

Hosmer and Lemeshow Test Chi-square $=10.93 ; p=0.21$;

Omnibus Tests of Model Coefficients Chi-square $=191.31(p<0.001)$.

Table 5

Mean serum SP-D values in $\mathrm{ng} / \mathrm{ml}$ in different genotypes

\begin{tabular}{lccc}
\hline$r s 3088308$ & & & \\
$\mathrm{~T} / \mathrm{T}$ & $\mathrm{A} / \mathrm{T}$ & $\mathrm{A} / \mathrm{A}$ & $($ ANOVA) $\mathrm{P}$ \\
$149.75 \pm 87.17$ & $111.16 \pm 62.51$ & $99.51 \pm 47.78$ & 0.01 \\
$r s 721917$ & & & \\
$\mathrm{~T} / \mathrm{T}$ & $\mathrm{C} / \mathrm{T}$ & $\mathrm{C} / \mathrm{C}$ & $($ ANOVA) $\mathrm{p}$ \\
$175.94 \pm 86.00$ & $127.24 \pm 81.31$ & $112.12 \pm 43.23$ & 0.02 \\
$r s 2243639$ & & & \\
$\mathrm{C} / \mathrm{C}$ & $\mathrm{C} / \mathrm{T}$ & $\mathrm{T} / \mathrm{T}$ & $($ ANOVA) $\mathrm{P}$ \\
$183.31 \pm 89.88$ & $129.08 .1 \pm 102.49$ & $148.35 \pm 27.36$ & 0.40 \\
\hline
\end{tabular}

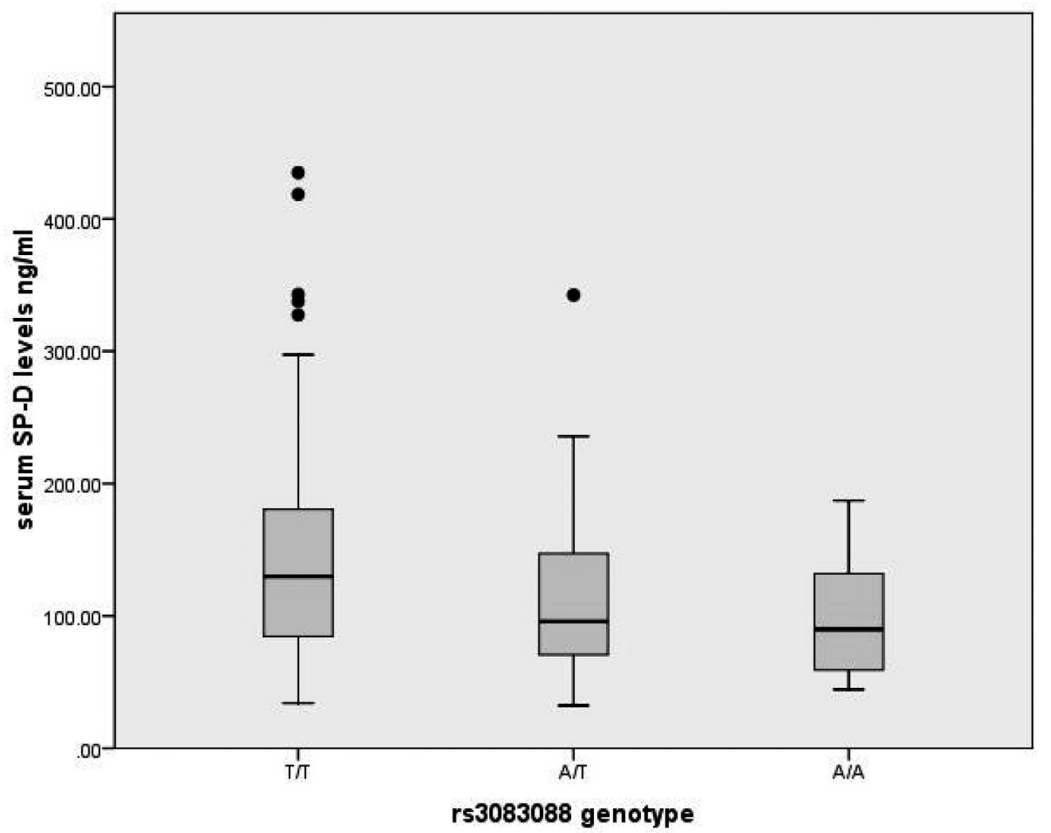

Fig. 5. Serum SP-D levels in genotypes of rs3088308 $(p=0.01)$. Note: The dots represent outliers within 1.5 inter-quartile ranges(IQR).

levels of SP-D were highest in T/T genotype $(149.75 \pm$ $87.17 \mathrm{ng} / \mathrm{ml})$, lower in genotype $\mathrm{A} / \mathrm{T}(111.16 \pm$ $62.51 \mathrm{ng} / \mathrm{ml})$ and lowest in genotype $\mathrm{A} / \mathrm{A}(99.51 \pm$ $47.78 \mathrm{ng} / \mathrm{ml}$ ). This pattern was significant at $p=0.01$. Similarly with rs721917, the highest SP-D values were recorded in genotype T/T $(175.95 \pm 86.00 \mathrm{ng} / \mathrm{ml})$, followed by $\mathrm{C} / \mathrm{T}(127.24 \pm 81.31 \mathrm{ng} / \mathrm{ml})$ and the lowest in $\mathrm{C} / \mathrm{C}(112.12 \pm 43.23 \mathrm{ng} / \mathrm{ml})$. These differences were also statistically significant at $p=0.02$. For rs2243639 there were no statistically significant differences between the three genotypes $(p=0.40)$.

\subsubsection{Determinants of serum SP-D levels}

Multiple linear regression analysis revealed the contribution of various predictor variables (including age, BMI, smoking status, exacerbation status, allele A at 
Table 6

The effect of different demographic, clinical and genetic factors on SP-D blood levels

\begin{tabular}{|c|c|c|c|c|c|}
\hline & \multirow[t]{2}{*}{ Predictor variables } & \multicolumn{2}{|c|}{$\begin{array}{c}\text { Unstandardized } \\
\text { coefficients }\end{array}$} & \multirow{2}{*}{$\begin{array}{c}\text { Standardized } \\
\text { coefficients } \\
\text { Beta }\end{array}$} & \multirow[t]{2}{*}{ 'P' } \\
\hline & & $\mathrm{B}$ & Std. Error & & \\
\hline & (Constant) & 4.81 & 0.99 & NA & $<0.001$ \\
\hline 1 & Exacerbation presence & 0.39 & 0.16 & 0.28 & $0.01^{*}$ \\
\hline 2 & Steroid use $\mathrm{a}^{\mathrm{a}}$ & -0.63 & 0.19 & -0.36 & $<0.001^{*}$ \\
\hline 3 & Smoking status & 0.06 & 0.19 & 0.04 & 0.75 \\
\hline 4 & 'A' allele at rs3088308 & -0.41 & 0.11 & -0.33 & $<0.001^{*}$ \\
\hline 5 & 'C' allele at rs721917 & -0.30 & 0.13 & -0.21 & $0.03^{*}$ \\
\hline 6 & Natural log of BMI & -0.69 & 0.26 & -0.26 & $0.01^{*}$ \\
\hline 7 & Natural log of age & 0.58 & 0.19 & 0.36 & $<0.001^{*}$ \\
\hline 8 & FEV $1 \%$ predicted & 0.003 & 0.002 & 0.18 & 0.16 \\
\hline
\end{tabular}

Dependent Variable: Natural log of Surfactant protein D serum levels; Regression Model's Adjusted R Square $=0.377$, ANOVA: $p<0.001$; BMI: Body mass Index, FEV1\% predicted: Forced expiratory volume in 1st second in litres percentage predicted for the age gender and ethnic background, NA: not applicable.

${ }^{\text {a }}$ Steroid intake at the time of sampling.

rs3088308, allele $\mathrm{C}$ at rs721917 and FEV1) to serum SP-D (Table 6). We found that ' $C$ ' allele at rs721917 $(p=0.03 ; B=-0.30)$ and 'A' at $\operatorname{rs3} 3088308(p<$ $0.001, B=-0.41)$ were significantly associated with decreased SP-D levels. Other significant contributors to serum SP-D levels included age $(p<0.001)$ body mass index $(p=0.01)$, exacerbation status $(p=0.01)$ and steroid intake $(p<0.001)$.

\section{Discussion}

The most important findings in this study are the correlation of SNPs rs721917 and rs3088308 with serum SP-D levels and of rs721917 with the risk of COPD. Single nucleotide polymorphism rs3088308 causes the substitution of nucleotide adenine (A) in place of a thymidine (T) in the seventh exon of the SFTPD gene leading to the replacement of serine (Ser) by threonine (Thr) at position number 270 in the carbohydrate recognition domain (CRD) of SP-D protein molecule. We found serum levels of SP-D in genotype A/A to be $11 \%$ lower as compared to heterozygotes (A/T) and $34 \%$ lower than genotype $\mathrm{T} / \mathrm{T}$ at $p=0.01$. We are reporting this association for the first time. Our study also confirmed the previously reported association of rs721917 with systemic SP-D levels [21,29]. In the current study, SP-D levels subjects with genotype C/C (of rs721917) were $12 \%$ lower than heterozygotes $(\mathrm{C} / \mathrm{T})$ and $36 . \%$ lower as compared to genotype $\mathrm{T} / \mathrm{T}$. The percentage difference between genotypes appears to be more in case of rs3088308 as compared to rs721917. A multiple regression model was developed to understand and quantify the effect of various genetic and environmen- tal factors on serum SP-D levels. As shown in Table 6, age $($ Beta $=0.36, p<0.001)$, and steroid intake (Beta $=-0.36, p<0.001)$ and rs3088308 influence serum SP-D levels (Beta $=-0.33, p<0.001)$ along with exacerbation status (Beta $=0.28, p=0.01)$, body mass index $($ Beta $=-0.26, p=0.01)$ and SNP rs721917 $($ Beta $=-0.21, p=0.03)$. Our study supports the previous studies correlating age [29], body mass index [31, 32], corticosteroid intake [33] and rs721917 [29,31,39] with systemic SP-D levels. We have previously reported on significantly raised serum SP-D levels in COPD exacerbations [34]. In the current study we confirm those findings using a larger sample size $(n=153)$ and a more comprehensive regression model incorporating genetic markers (rs3088308 and rs721917) as covariates. Thus we show that even when genetic factors are considered, exacerbation remains a significant determinant of systemic SP-D levels. These data highlight the potential utility of serum SP-D as a biomarker for exacerbations as previously reported [34]. A study by Sims et al. [35] reports on decreased SP-D levels in broncho-alveolar lavage fluid (BALF) of COPD patients and that these levels increased after corticosteroid therapy. This is consistent with our findings since alveolar damage in COPD causes leakage of SP-D from the pulmonary compartment into the systemic circulation resulting in lowered BALF but high serum SP-D levels. Similarly steroid therapy stimulates the production of SP-D, leading to inmcreased levels in BALF. Steroids also control the inflammatory reaction of COPD and restore the integrity of alveolar membrane which explains lower serum SP-D levels in patients on corticosteroid therapy [35].

Why amino acid substitutions would affect serum levels of SP-D is unknown. It is widely believed that 


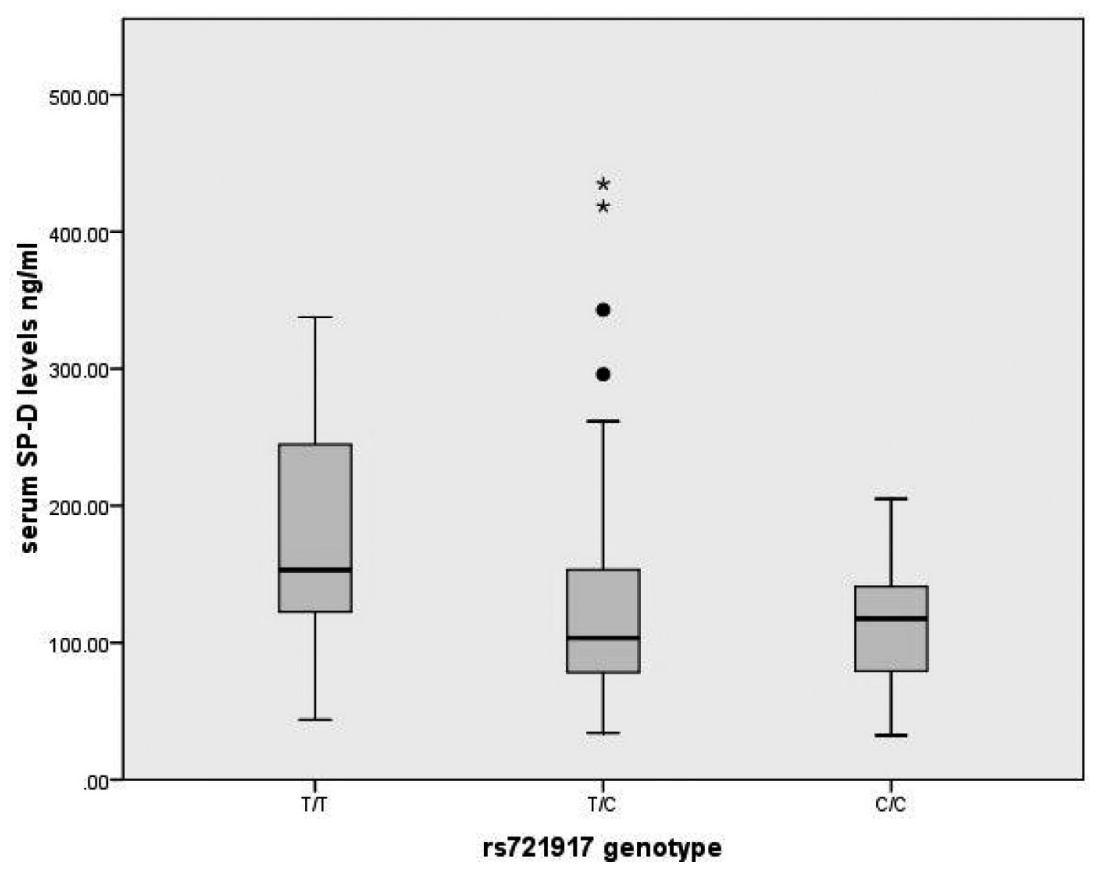

Fig. 6. Serum SP-D levels in genotypes of rs721917 $(p=0.02)$. Note: The dots represent outliers within 1.5 IQR while $*$ represents outliers within 3 IQR.

the predominant source of systemic SP-D is via leakage from the alveolar compartment [36,37]. It is possible that even slight alterations in the molecular structure of SP-D may modify the function of SP-D, perhaps disturbing balance between its immuno-stimulatory and immuno-modulatory roles. Altered defence capabilities of this key innate immune molecule may lead to an abnormal inflammatory response to environmental insults which may in turn compromise the integrity of the alveolar membrane, increasing the amount of SP-D that leaks into the circulation. More research is however required to investigate the exact mechanisms.

The other important finding of our study is the association of genotype 'T/T' of rs 721917 or the 'Met variant' with the risk of COPD. Genotype distributions in cases for rs 721917 deviated significantly from Hardy Weinberg Equilibrium, giving an early hint of possible association of these SNPs with COPD $(p<0.001)$. Chi square test showed that genotype distributions between cases and controls indeed did differ significantly for rs721917 at $p=0.038$ respectively. When the risk of COPD was assessed in the presence of age, smoking history and body mass index using a multiple linear regression model, rs721917 remained significantly associated with the risk of COPD (odds ratio $=11.17$, $p=0.01)$. These data raise the possibility of SNP analysis in early detection of 'at risk smokers' for this progressive disease with no cure.
Our finding is in contrast to a previous study by Foreman et al. [21] who found the $\mathrm{C}$ allele to be associated with COPD. There are several possible reasons for this discrepancy. Although Foreman's study was larger than our study, they used the NETT (National Emphysema Treatment Trial) subjects who had bilateral emphysema and with FEV1 of $<45 \%$. Thus these subjects represented one extreme phenotype of COPD. This may be one of the reasons why Foreman's findings were not replicated in the 'Bergen cohort' or by the "ECLIPSE" Study Group. Another reason for the differences in results could be variation in the genetic backgrounds of subjects. This phenomenon has been well described by Brandt and coworkers [22]. They used the same protocol on black and white subjects but found the 'Met allele' to be associated with atopy and asthma in only black subjects. Genetic and phenotypic difference would also explain the contrasting findings by Ishii et al. [41]. It is also notable that serum SP-D is increased in COPD as compared to controls [33]. As higher SP-D levels are linked with ' $T$ ' allele [22,29], our finding of the association of COPD with ' $\mathrm{T}$ ' allele of rs721917 is consistent with this observation.

Several studies have previously linked rs 721917 with various pathologies. Allele $\mathrm{C}$ (threonine variant) has been related with susceptibility to tuberculosis [18] and allergic rhinitis [20] whereas allele ' $\mathrm{T}$ ' (methion- 
ine variant) has been connected with respiratory syncitial virus (RSV) infection in infants [17] and atopy in asthma [22].

There are several limitations to our study. First, due to the modest sample size, we cannot entirely rule out the associations of the other two polymorphisms with COPD. Second, all our subjects were men. Although this limits the general application of our findings, on the positive side, this removed confounding by gender to our findings [38]. It should be also noted that we recruited patients with the same ethnicity (Pakistani Punjabi), which reduced the genetic heterogeneity in our study. Third the control population is not in Hardy Weinberg equilibrium for rs3088308. This has the potential of false positive associations in genetic association studies. However we did not find any association of SNP rs3088308 with COPD risk to begin with. The SNP which did show association with COPD did not depart from Hardy Weinberg equilibrium. Fourth, we evaluated only three SNPs, one from each functional domain of the molecule. The SNP rs721917 affects the $\mathrm{N}$ terminal domain (potentially disturbing multimerization of the molecules), rs2243639 affects collagen domain (disrupting collagen domain mediated immunological interactions) and rs3088308 affects the carbohydrate recognition domain (the main ligand binding domain). Five other coding SNPs have been described in public databases such as NCBI. A larger study including all the eight coding SNPs may provide additional insight on the role of SP-D in COPD. Finally we did not show significant correlations of smoking with either serum SP-D levels [40] or risk of COPD [35] in our study group. This may be due to the modest sample size or the fact that many of the patients were ex smokers with significant smoking history who had quit smoking but their disease progressed as is the general pattern. Still another reason for lack of finding an association between smoking and serum SP-D or COPD risk could be that our control group was predominantly composed of smokers with normal lung functions. This group could well be resistant to harmful effects of cigarette smoke.

\section{Conclusions}

The single nucleotide polymorphisms of SFTPD, rs721917 and rs3088308 are major determinants of serum SP-D levels and genotype T/T of SNP rs721917 is a risk factor for COPD.

\section{Venues of research}

Sampling: Pulmonology Department, Shaikh Zayed Medical Complex and Gulab Devi Chest Hospital, Lahore, Pakistan.

Spirometry: Heart Lung Lab, SZMC and Gulab Devi Chest Hospital Lahore, Pakistan.

Genetic Analysis: School of Biological Sciences, University of the Punjab, Lahore, Pakistan.

ELISA: Immunoassay lab, National Health Research Complex, SZMC, Lahore, Pakistan.

\section{Funding}

The funding for kits was provided by Higher Education Commission, Pakistan as a part of Indigenous $\mathrm{PhD}$ scholarship program.

\section{COI Disclosures: None of the authors have any conflicts of interests to declare}

Informed consent was taken from all participants and the study conforms to the Code of Ethics of the World Medical Association (Declaration of Helsinki), printed in the British Medical Journal (18 July 1964).

\section{References}

[1] L. Fromer and C.B. Cooper, A review of the GOLD guidelines for the diagnosis and treatment of patients with COPD, Int J Clin Pract 62 (2008), 1219-1236.

[2] R.T. Abboud and S. Vimalanathan, Pathogenesis of COPD. Part I. The role of protease-antiprotease imbalance in emphysema, Int J Tuberc Lung Dis 12 (2008), 361-367.

[3] W. MacNee, Pulmonary and systemic oxidant/antioxidant imbalance in chronic obstructive pulmonary disease, Proc Am Thorac Soc 2 (2005), 50-60.

[4] J.C. Hogg, Pathophysiology of airflow limitation in chronic obstructive pulmonary disease, Lancet 364 (2004), 709-721.

[5] K. Imai, B.A. Mercer, L.L. Schulman, et al., Correlation of lung surface area to apoptosis and proliferation in human emphysema, Eur Respir J 25 (2005), 250-258.

[6] S. Grumelli, D.B. Corry, L.Z. Song, et al., An immune basis for lung parenchymal destruction in chronic obstructive pulmonary disease and emphysema, PLoS Med 1 (2004), 75-83.

[7] M.G. Cosio, Autoimmunity, T-cells and STAT-4 in the pathogenesis of chronic obstuctive pulmonary disease. Eur Respir J 24 (2004), 3-5.

[8] B.G. Cosio, L. Tsaprouni, K. Ito, et al., Theophylline restores histone deacetylase activity and steroid responses in COPD macrophages, J Exp Med 200 (2004), 689-695.

[9] W. MacNee, Accelerated lung aging: A novel pathogenic mechanism of chronic obstructive pulmonary disease (COPD), Biochem Soc Trans 37 (2009), 819-823. 
[10] P.J. Boron, E.A. Mostaghel, C. Doyle, et al., Pulmonary surfactant protein A and D directly suppress CD3(+)/CD4(+) cell function: evidence for two shared mechanisms, J Immunol 169 (2002), 5844-5850.

[11] S.J. Gardai, Y.Q. Xiao, M. Dickinson, et al., By Binding SIRP $\alpha$ or calreticulin/CD91, lung collectins act as dual function surveillance molecules to suppress or enhance inflammation, Cell 115 (2003), 13-23.

[12] R.W. Vandivier, C.A. Ogden, V.A. Fadock, et al., Role of surfactant proteins $\mathrm{A}, \mathrm{D}$ and $\mathrm{Clq}$ in clearance of apoptotic cells in vivo and in vitro: calreticulin and CD91 as a common collectin receptor complex, J Immunol 169 (2002), 3978-3986.

[13] N. Palaniyar, H. Clark, J. Nadesalingama, et al., Surfactant protein D binds genomic DNA and apoptotic cells, and enhances their clearance in vivo. Apoptosis: from Signaling Pathways, Therapeutic Tools 1010 (2003), 471-475.

[14] N. Palaniyar, J. Nadesalingama, H. Clark, et al., Nucleic acid is a novel ligand for innate immune pattern recognition collectins surfactant proteins $\mathrm{A}$ and $\mathrm{D}$ and mannose-binding lectin, J Biol Chem 279 (2004), 32728-32736.

[15] N. Palaniyar, H. Clark, J. Nadesalingama, et al., Innate immune collectin surfactant protein D enhances the clearance of DNA by Macrophages and Minimizes Anti-DNA Antibody Generation, J Immunol 174 (2005), 7352-7358.

[16] S. DiAngelo, Z. Lin, G. Wang, et al., Novel, Non-radioactive, simple and multiplex PCR-cRFLP methods for genotyping human SP-A and SP-D marker alleles, Dis Markers 15 (1999), 269-281.

[17] M. Lahti, J. Lofgren, R. Marttila, et al., Surfactant protein D gene polymorphism associated with severe respiratory syncytial virus infection, Pediatr Res 51 (2002), 696-699.

[18] J. Floros, H.M. Lin, A. Garcia, et al., Surfactant protein genetic marker alleles identify a subgroup of tuberculosis in a Mexican population, J Infect Dis 182 (2000), 1473-1478.

[19] K.L. Hartshorn, M.R. White, K. Smith et al., Increasing antiviral activity of surfactant protein $\mathrm{d}$ trimers by introducing residues from bovine serum collectins: Dissociation of mannan-binding and antiviral activity. Scand J Immunol 72 (2010), 22-30.

[20] Y.Q. Deng, Z.Z. Tao, Y.G. Kong, et al., Association between single nucleotide polymorphisms of surfactant protein $\mathrm{D}$ and allergic rhinitis in Chinese patients, Tissue Antigens 73 (2009), 546-552.

[21] M.G. Foreman, X. Kong, D.L. DeMeo, et al., Polymorphisms in surfactant protein-D are associated with chronic obstructive pulmonary disease, Am J Respir Cell Mol Biol 44 (2011), 316-322.

[22] E.B. Brandt, M.K. Mingler, M.D. Stevenson, et al., Surfactant protein $\mathrm{D}$ alters allergic lung responses in mice and human subjects, J Allergy Clin Immunol 121 (2008), 1140-1147.

[23] R. Leth-Larsen, C. Nordenbaek, I. Tornoe, et al., Surfactant D (SP-D) serum levels in patients with community-acquired pneumonia, Clin Immunol 108 (2003), 29-37.

[24] M. Tanaka, Y. Arimura, A. Goto, et al., Genetic variants in surfactant, pulmonary-associated protein D (SFTPD) and Japanese susceptibility to ulcerative colitis, Inflamm Bowel Dis 15 (2009), 918-925.

[25] N.J. Thomas, S. DiAngelo, J.C. Hess, et al., Transmission of Surfactant Protein Variants and Haplotypes in Children Hos- pitalized with Respiratory Syncytial Virus, Pediatr Res 66 (2009), 70-73.

[26] S. Burge and J.A. Wedzicha, COPD exacerbations: definitions and classifications, Eur Respir J 21 (2003), S46-S53.

[27] S.A. Miller, D.D. Dykes and H.F. Polesky, A simple salting out procedure for extracting DNA from human nucleated cells, Nucleic Acids Research 16 (1988), 1215.

[28] M. Krueger, B. Puthothu, E. Gropp, et al., Amino acid variants in Surfactant protein D are not associated with bronchial asthma, Pediatr Allergy Immunol 17 (2006), 77-81.

[29] G.L. Sørensen, J.B. Hjelmborg, K.O. Kyvik, et al., Genetic and environmental influences of surfactant protein D serum levels, Am J Physiol Lung Cell Mol Physiol 290 (2006), L1010-1017.

[30] Y.Y. Shi and L. He, SHEsis, a powerful software platform for analyses of linkage disequilibrium, haplotype construction, and genetic association at polymorphism loci, Cell Res 15 (2005), 97-98.

[31] X.M. Zhao, Y.P. Wu, R. Wei, et al., Plasma surfactant protein $\mathrm{D}$ levels and the relation to body mass index in a Chinese population, Scand J Immunol 66 (2007), 71-76.

[32] J.M. Fernández-Real, S. Valdés, M. Manco, et al., Surfactant protein $\mathrm{d}$, a marker of lung innate immunity, is positively associated with insulin sensitivity, Diabetes Care 33 (2010), 847-853.

[33] D.A. Lomas, E.K. Silverman, L.D. Edwards, et al., Serum surfactant protein D is steroid sensitive and associated with exacerbations of COPD, Eur Respir J 34 (2009), 95-102.

[34] T.A. Shakoori, D.D. Sin, F. Ghafoor, et al., Serum surfactant protein D during acute exacerbations of chronic obstructive pulmonary disease, Dis Markers 27 (2009), 287-294.

[35] M.W. Sims, R. M. Tal-Singer, S. Kierstein, et al., Chronic obstructive pulmonary disease and inhaled steroids alter surfactant protein D (SP-D) levels: a cross-sectional study. Respiratory Research 9 (2008), 13.

[36] D.D. Sin, P.S. Pahlvan and S.F.P. Man, Surfactant protein D: A lung specific biomarker in COPD? Ther Adv Resp Dis 2 (2008), 65-74.

[37] G.R. Mason, A.M. Peters, E. Bagdades, et al., Evaluation of pulmonary alveolar epithelial integrity by the detection of restriction to diffusion of hydrophilic solutes of different molecular sizes, Clin Sci (Lond) 100 (2001), 231-236.

[38] E. Prescott, A.M. Bjerg, P.K. Andersen, et al., Gender difference in smoking effects on lung function and risk of hospitalization for COPD: results from a Danish longitudinal population study, Eur Resp J 10 (1997), 822-827.

[39] K. Heidinger, I.R. Konig, A. Bohnert, et al., Polymorphisms in the human surfactant protein-D (SFTPD) gene: strong evidence that serum levels of surfactant protein-D (SP-D) are genetically influenced, Immunogenetics 57 (2005), 1-7.

[40] M. Mutti, M. Corradi, M. Goldoni, et al., Exhaled metallic elements and serum pneumoproteins in asymptomatic smokers and patients with COPD or asthma, Chest 129 (2006) 12881297.

[41] T. Ishii, K. Haqiwara, K. Kamio, et al., Involvemement of surfactant protein $\mathrm{D}$ in emphysema revealed by genetic association study, Eur J Hum Genet 2011 Sep 21. doi: 10.1038/ejhg. 2011.183. [Epub ahead of print]. 


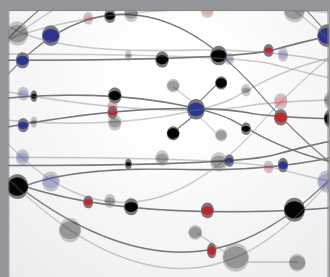

The Scientific World Journal
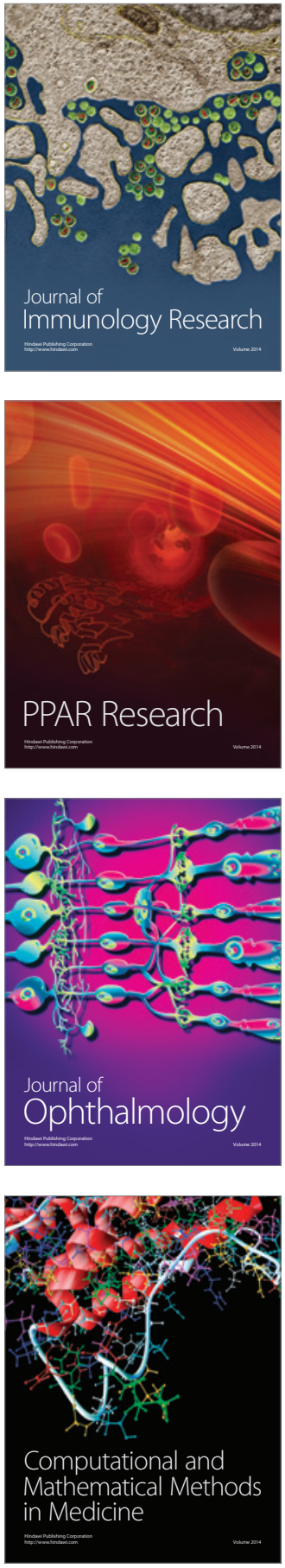

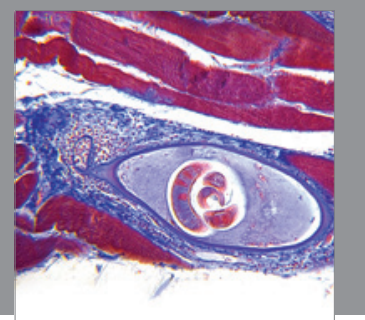

Gastroenterology

Research and Practice
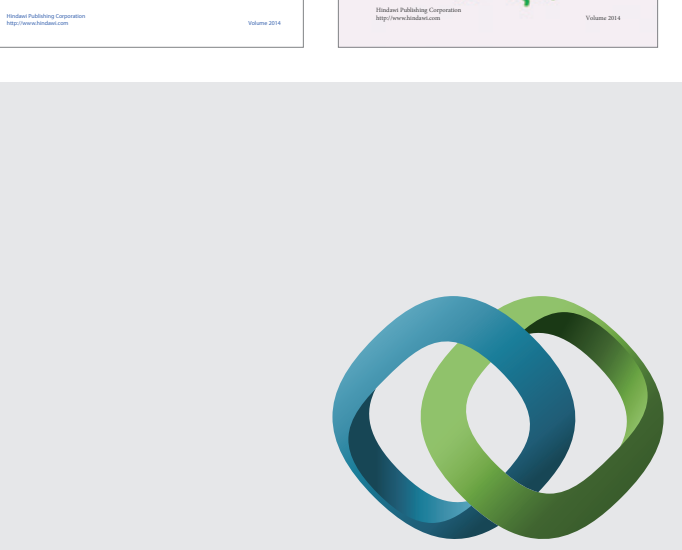

\section{Hindawi}

Submit your manuscripts at

http://www.hindawi.com
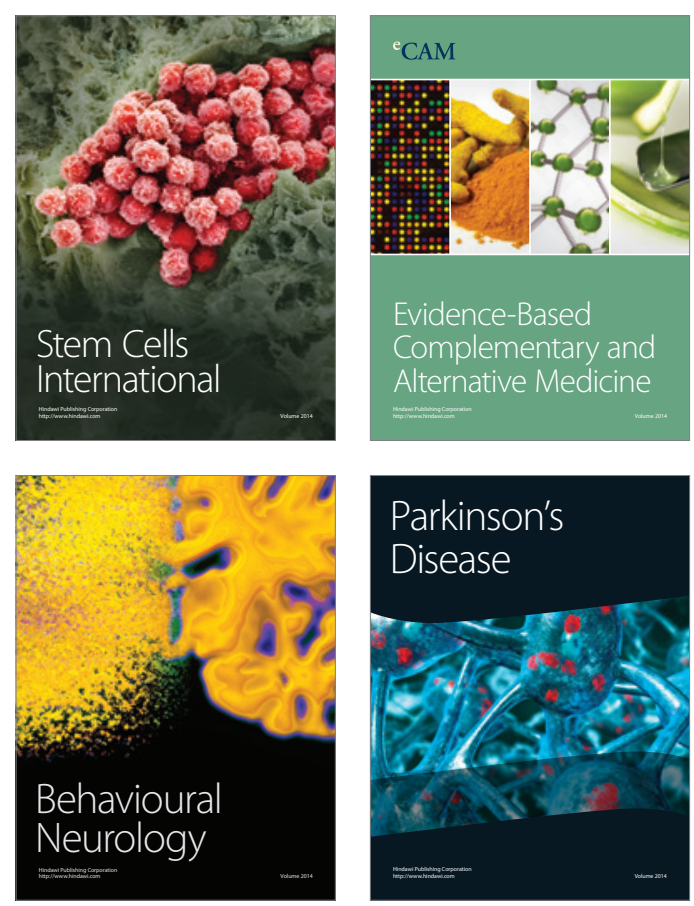

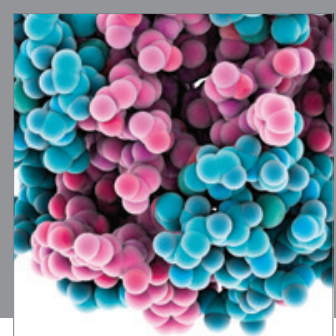

Journal of
Diabetes Research

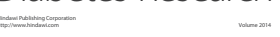

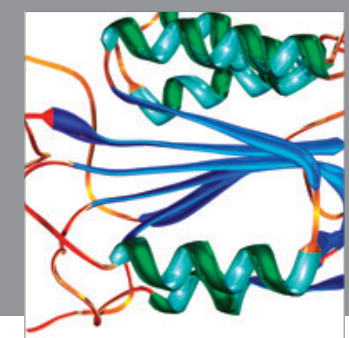

Disease Markers
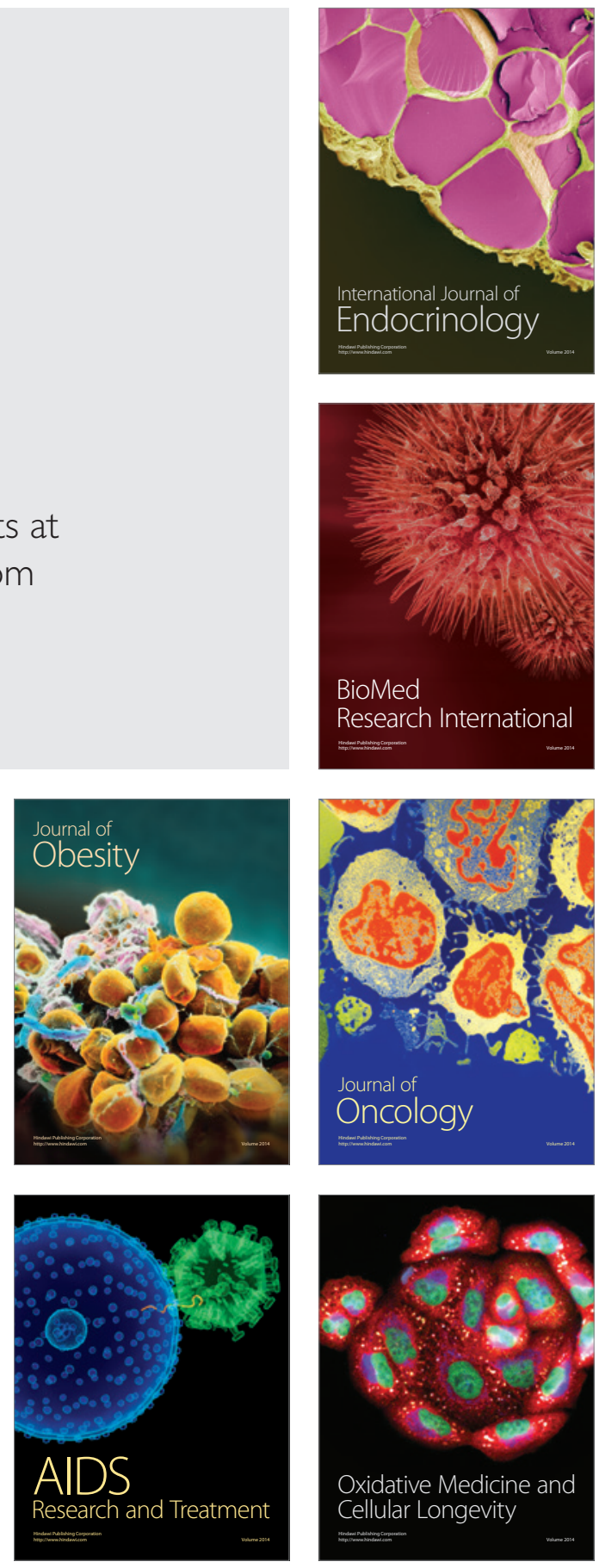